\title{
SINGLE-ITEM LOT-BASED SUPPLYING AND BATCH PRODUCTION UNDER A BILATERAL CAPACITY RESERVATION: A PARTNERSHIP STRUCTURE
}

\author{
SAEID REZAEI AND JAVAD BEHNAMIAN*
}

\begin{abstract}
This paper studies a single-item lot-based supplying and batch production under a bilateral capacity reservation contract based on a partnership structure in which some suppliers, a manufacturer, and a third-party logistics provider are connected through long-term cooperation agreements. This configures a partnership supply chain and promotes the manufacturer's performance in a continuous improvement cycle. Since in this paper, it is assumed that the products are perishable, there is not any inventory storage. Moreover, due to a settled contract, the final products are delivered by third-party logistics corporate providing vehicles according to the products' features, their expiration time lengths, customers' demands and other considerations in each period. Thus, the delivery batch size, which is equal to the vehicle capacity in a full truckload mode, is targeted for the manufacturer operations resulting in a dynamic improvement environment. In this problem, respect to the performance level of the manufacturer, in each period, a certain capacity is reserved at each selected supplier level according to the appointed batch deliveries. Here, in addition to the ordinary costs incurred due to ordering and delivery processes, some penalties are imposed for orders/delivers exceeding or falling behind the reserved capacity. After investigating the computational complexity of the problem, we propose three dynamic programming algorithm as well. Finally, numerical results and some potential future researches are presented.
\end{abstract}

Mathematics Subject Classification. 90B06, 90B30, 90C39.

Received March 5, 2020. Accepted September 8, 2020.

\section{INTRODUCTION}

A lot of researches that have been carried out in the field of the single-item lot-sizing problem (SILSP) and its corresponding issues, indicates the interesting aspects of SILSP when scheming the procurement of raw materials associated with ordering and transshipment charges [25]. Since manufacturing and remanufacturing capacities, production and delivery time-windows, bounded inventory, backlogging, and perishability encompass various dimensions of the SILSP, efficiently solving it is also critical [9].

The SILSP can be described as a problem representing variable demands for a single item during a planning horizon. The goal of planning is to specify periods in which manufacturing will occur and the sizes that have to be manufactured [4]. The manufacturing aims at meeting the entire demands, along with minimizing the

Keywords. Supply chain management, batch-production, partnership supply, bilateral capacity reservation contract, dynamic programming algorithm.

Department of Industrial Engineering, Bu-Ali Sina University, Hamedan, Iran.

* Corresponding author: Behnamian@basu.ac.ir 
whole costs. The associated primary charges consist of the unit manufacturing cost, the setup cost, and the unit inventory holding cost [10]. In another point of view, there is always some waste in production processes resulted from supplying and/or manufacturing functions leading to a hierarchical change in decisions corresponding to different echelons of supply chains. Assuming that every product has a life cycle, Khan et al. [14] suggested a price discount strategy in the present business environment. Based on the cited concepts, they considered two supply chain models where shortages either are not allowed or may occur with partial backorders. As the holding cost per unit cannot be constant in the entire cycle length, they regarded it as a linearly increasing function of the storage time. Further, in spite of the most carried out researches in the corresponding scope, they presumed the unit purchasing cost as a decreasing function of the order size and provided a discount-based situation as well.

Since the majority of the holding charges are not always fixed due to uncertainty of today's competitive environment, Shaikh et al. [21] studied a two-warehouse model with interval-valued inventory cost and advance payment for deteriorating items under particle swarm optimization. In this regard, they took into account the inventory parameters as intervals and also assumed partially backlogged shortages in effect. To cope with the uncertainty arising from the real situations, they used some interval arithmetic and interval order relations and developed different variants of particle swarm optimization techniques to efficiently solve the problem. Pointing out the price and stock as two important factors in inventory analyses, Panda et al. [19] investigated a trade credit policy and provided a two-warehouse inventory formulation. In addition, they included the deteriorating factor with a price- and stock-dependent demand under partially backlogged shortage. The problem assumptions are: (i) price- and stock-dependent demand, (ii) price as a constant markup rate, (iii) backlogging rate as length of the waiting time of the customers, (iv) alternative trade credit policy, and (v) advertisement of the product. Due to the nonlinearity of the problem, they were not able to optimally solve the problem and only performed the sensitivity analyses in effect.

Advance payment is of highly impressive factor in SILSP schemes. The main target of each inventory control system is improving the total benefits of firms without decreasing the customers' satisfaction and also service levels [22]. On the other hand, usually, the cost of an order is spent at delivery time, while prepayment for some special products is commonly requested from the supplier ensuring that the purchaser never cancels the order. Khan et al. [15] investigated an advance payment scheme which is made by equal installment up to $n$ times before receiving the products. They developed a two-warehouse inventory model for deteriorating items and assumed shortages with a constant partial backlogging rate. With the aim of encouraging buyers to increase their orders, vendors sometimes offer them to pay all or a proportion of the purchasing cost after receiving the items. In this regard, Taleizadeh et al. [23] considered the customer's inventory policy by considering two different conditions: (i) full prepayment with shortage, (ii) partial prepayment-partial delayed payment with shortage. As such, they investigated the effect of parameters such as price discounts linked to prepayment and length of prepayment on optimal periods of inventory and shortage quantity. Taking into cognizance the different situations of deterioration (and despite the ordinary assumption in the existing models), Khan et al. [16] discussed that the decay in owned warehouse begins earlier than that in the case of the rented warehouse. They formulated a two-storage inventory model with advance payment under three different situations according to different possibilities of starting times of deterioration in both warehouses. Observing that suppliers give different kinds of benefits to retailers due to advance payment, Khan et al. [17] studied a problem under both cases of advance payment (full or partial), an inventory model for deteriorating products where shortages are allowed and demand function is considered as price and stock dependent.

The SILSP with allowed shortages was first considered by Zangwill [26]. Indeed, it can be due that the cost of providing and warehousing the products is not beneficial or the available capacity is not adequate to meet entire demands on assigned schedules. In this regard, the backorders are formulated through the variables of newly manufactured products-flow which are at the contrary direction of the ones relating to the inventory flow [8]. In similar cases with the uncapacitated SILSP, the utmost optimal solutions make spanning-tree configurations. Zangwill [26] showed that the problem is optimally solvable in $\mathrm{O}\left(T^{2}\right)$ by generalizing the Wagner-Whitin algorithm. By applying similar techniques (the techniques similar to the ones utilized for the uncapacitated 
SILSP), the complexity of the problem was decreased to $\mathrm{O}(T \log T)$ or $\mathrm{O}(T)$ [7]. As companies constantly need free cash flows to efficiently react to any uncertainty, Bian et al. [5] developed a two-level uncapacitated lot-sizing problem considering the financing cost of working capital requirement. They proposed sequential and centralized approaches to solve the two-level case with a serial chain structure and established a dynamic programming-based algorithm in effect.

Several studies considered the uncapacitated SILSP with backlogging and demonstrated that the problem can be often solved by polynomial-time algorithms. Absi et al. [1] studied the uncapacitated SILSP with backlogging costs and also production time windows, and indicated that the problem is optimally solvable through a dynamic programming algorithm with the complexity of $\mathrm{O}\left(T^{2}\right)$. Chu et al. [11] generalized the uncapacitated SILSP (with backlogging) by incorporating outsourcing and inventory capacity and showed that the problem can be solved in $\mathrm{O}\left(T^{4} \log T\right)$. Van Vyve [24] considered two linear programming models in the lot-sizing problem with constant-capacity and backlogging. The first one presents a general cost function with the complexity of $\mathrm{O}\left(T^{3}\right)$, and the second deals with the problem having $\mathrm{O}\left(T^{2}\right)$ variables and $\mathrm{O}\left(T^{3}\right)$ constraints. Hwang and Kang [13] investigated a two-level lot-sizing problem with stepwise transportation costs and backlogging within an integrated replenishment and dispatch plan. Assuming the capacitated and uncapacitated lot-sizing characteristics, they developed an improved $\mathrm{O}\left(T^{4}\right)$ algorithm where $T$ is the length of the planning horizon. Phouratsamay et al. [20] provided a two-level uncapacitated lot-sizing problem with inventory bounds that occurs in a supply chain composed of a supplier and a retailer. They assumed that the inventory bounds can be imposed at the retailer level, at the supplier level or at both levels and proposed a polynomial dynamic programming algorithm to solve the problem. Also, they proved that the uncapacitated lot-sizing problem with inventory bounds is strongly NP-hard and utilized a pseudo-polynomial algorithm that solves this problem when there are inventory bounds on both levels.

In this paper, we consider a novel and practical approach in the field of SILSP based on a lot-supplying and batch-production strategy. Indeed, as there is inevitably some waste in every production process, implementing an efficient mechanism is critical to achieve the intended goals. In this regard, the quantity of raw materials is delivered in lots by selected external suppliers with the best contract terms, and the production is fulfilled in batches (e.g., pallet, truck, etc.). This procedure leads to a worthy competition between the suppliers for offering a preferable contract, and also makes the manufacturers to implement an advantageous maintenance and repair planning for keeping the consistency in the production conditions.

In this context, after choosing the qualified suppliers for long-term cooperation, short-term reservation contracts are conducted between the manufacturer and some of them based on an anticipated level of waste incurred in each period. Up to a certain level of the reserved capacity, the raw materials have a certain beneficial unit cost, and once the size of the order exceeds the predetermined level, the suppliers offer a second higher price.

In our problem, the production batch size must be the same as the vehicle capacity in a full truckload (FTL) shipment policy in each period, leading to an advantageous approach in fulfilling the customers' demands further in case the products are perishable or soon-expired. In addition to the classical SILSP problem, there exist two types of variable costs per order, respectively, for the orders above the reserved capacity and below it. In this strategy, once the order quantity is exceeded the specified level, the surplus numbers can be procured from other suppliers placed in the next ranks based on increasing total costs.

For the problem considered in this paper, the manufacturer accepts to pay a primary cost $S_{0}$ as the fixed ordering charge (also includes contract signing expenditures), and reserves a capacity $V_{t}$ in the chosen supplier for each period. While the amount of order in period $t$ is less than $V_{t}$, the manufacturer is committed to pay a unit cost of $a_{t}$ and also a unit penalty cost of $p_{t}$ for the difference up to the agreed level. But in case the order exceeds the reserved level, a cost of $b_{t}$ is incurred for each unit of raw materials. As mentioned, these extra units may be procured from the second affordable supplier. Figure 1 shows the cost structure for a sample supplier according to the reserved capacity.

Similarly, as shown in Figure 2, it is set another contract with the third-party logistics provider based on batches reserved to deliver in each period (also again after signing the long-term agreement). In this context, as the products are soon-expired and need corresponding requirements of batching and delivering, the production 


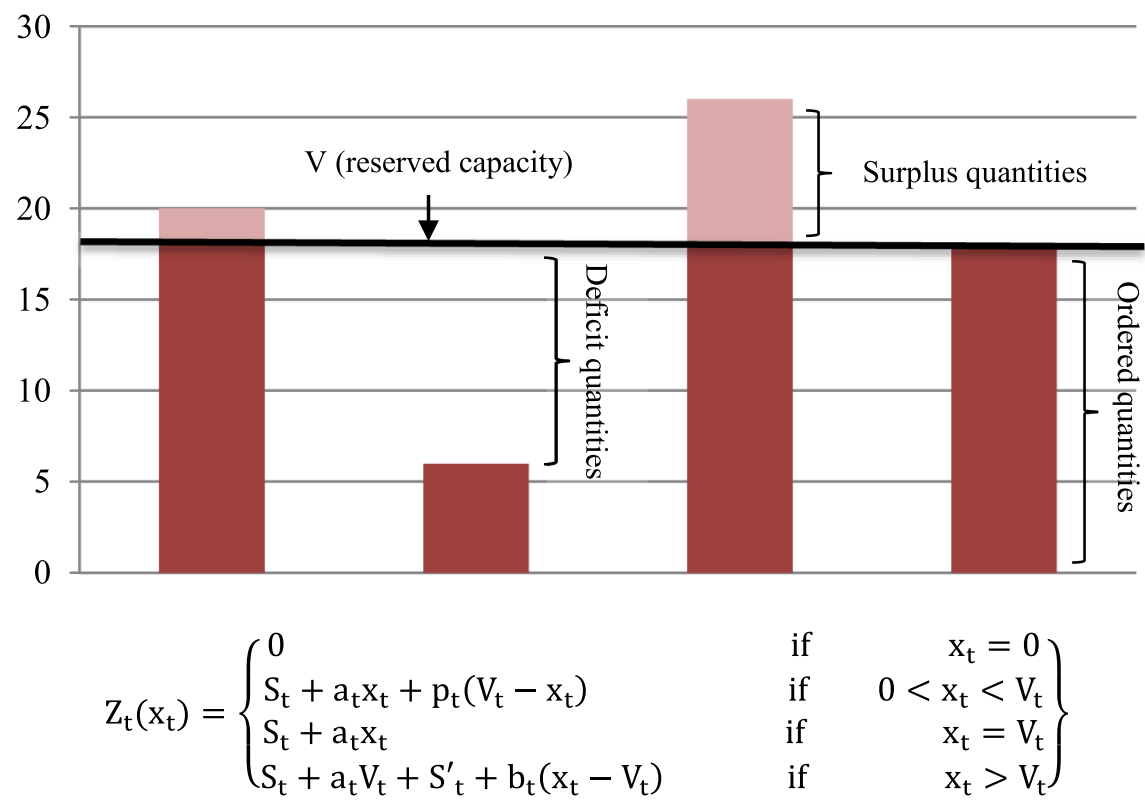

Figure 1. Structure of the problem in the supplier side with lot-based deliveries under a capacity reservation contract.

batches do not exceed the reserved number at the logistics corporate-level. Therefore, only a penalty charge is incurred by the logistics service in case the manufactured batches fall less than the reserved number.

Hence, compared with the most similar researches done in the corresponding area (as reviewed above), this paper contributes to the literature in the following ways:

- Developing single-item lot-based supplying and batch production structure (different from the common procedures in classical SILSPs).

- (Even more striking) utilizing a bilateral reservation mechanism (making the manufacturer proceed based on a dynamic improvement structure, providing a joint procedure in responding to the demands).

- Using a partnership supply strategy where the manufacturer is a focal point of the network (this results in an increased synergy in the network through which each member (level) is responsible for the customers' satisfaction).

- Considering manufacturing losses with the aim of providing a balanced production condition (this can extend a realistic and practical approach in the supply chain functions).

- Newly taking into account a batch-production formulation according to the perishability and other corresponding features of the products.

- Investigating the complexity of the problem.

- Proposing three DP-based algorithms in order to reduce the complexity of the problem.

The paper is further organized as follows. In Section 2, we state the problem in detail and formulate it based on MILP modeling. Section 3 is dedicated to the investigation of the problem complexity. Section 4 is assigned to proposing three dynamic programming algorithms for solving the problem. Finally, Section 5 concludes the paper and suggests some potential features for future studies. 


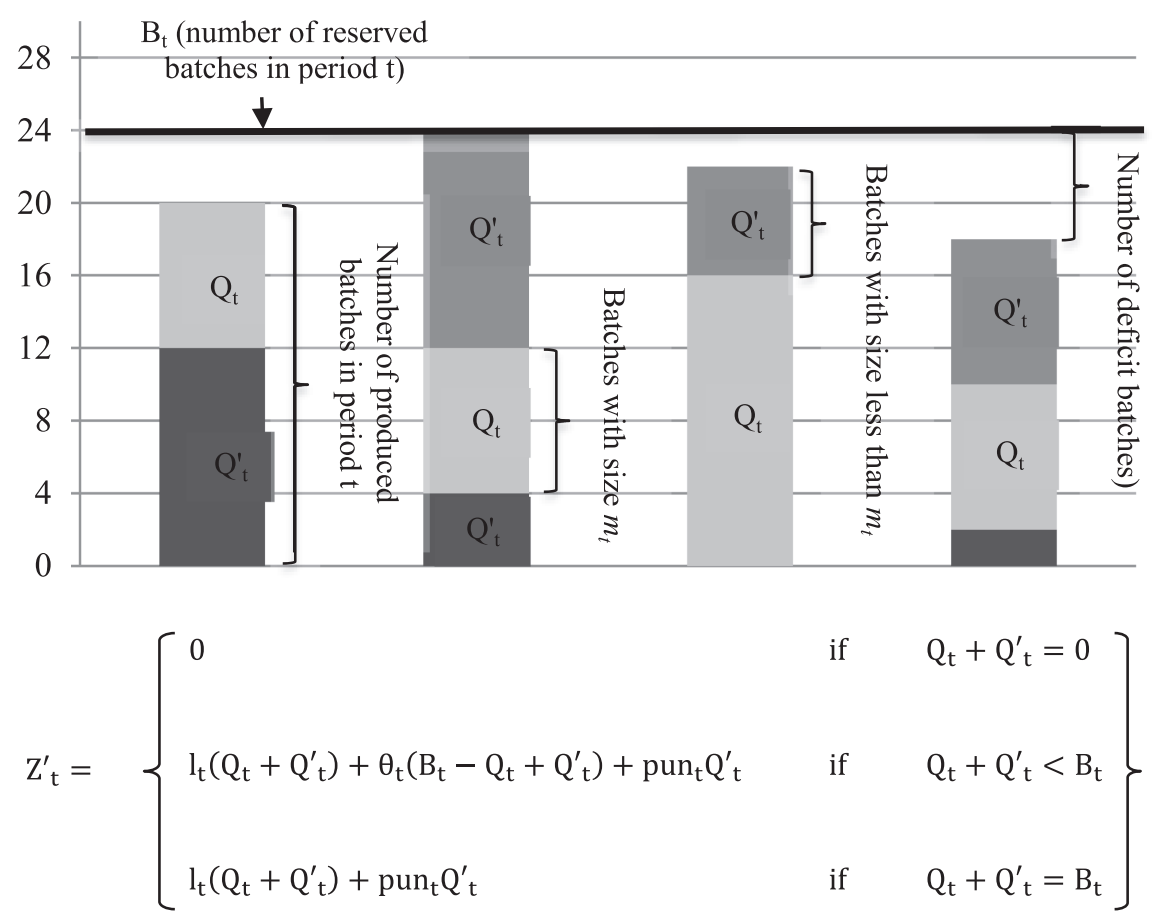

FiguRE 2. Structure of the problem in the distribution side with batch deliveries under a capacity reservation contract.

\section{Problem statement}

As discussed previously, there always exists some waste in every production process stemming from incompatibility (or not meeting the desired features) in the corresponding operations. Here, we are to expand the think of developing a partnership supply mechanism in a particular supply chain leading to a progressive performance of the manufacturer. For this purpose, the manufacturer tries to improve its procedures and reduce the production losses; eventually, achieves an invariant operating condition. Hence, we offer a lot-supplying and batch-production strategy (LSBPS) aiming to obtain a balanced manufacturing process resulting in satisfying the taken demands of the customers entirely. Consider Figure 3, where a manufacturer is replenished by some suppliers in lot-based deliveries. The admitted demands of the product (determined by the manufacturer according to the customers' demands, products' requirements, carriers' capabilities, and other considerations) in each period is deterministic and known in advance. Each supplier proposes a capacity reservation contract and has a limited valence. In addition, each supplier tries to motivate the manufacturer by propounding a preferable contract. Raw materials could be shipped whether in an economical procedure (based on reserved numbers) or not (for exceeding numbers), implying distinct transportation charges for each order. According to pre-signed contracts, up to a certain level, the raw materials have an appointed beneficial unit cost. Once the size of the order exceeds the pre-specified level, the suppliers offer a second higher price and also a new ordering and contract costs. Actually, this second price is imposed due to setting up and again manufacturing the surplus demands. On the other hand, a penalty cost is also incurred in case the orders do not reach the size previously agreed through a contract. Hence, the manufacturer tries to keep stable production processes via developing an efficient maintenance \& repair system, and eventually not to violate the contract terms.

On the other hand, we consider another contract setting with the logistics corporate based on batches reserved to deliver in each period. Toward this end, as the products are perishable and need corresponding requirements 


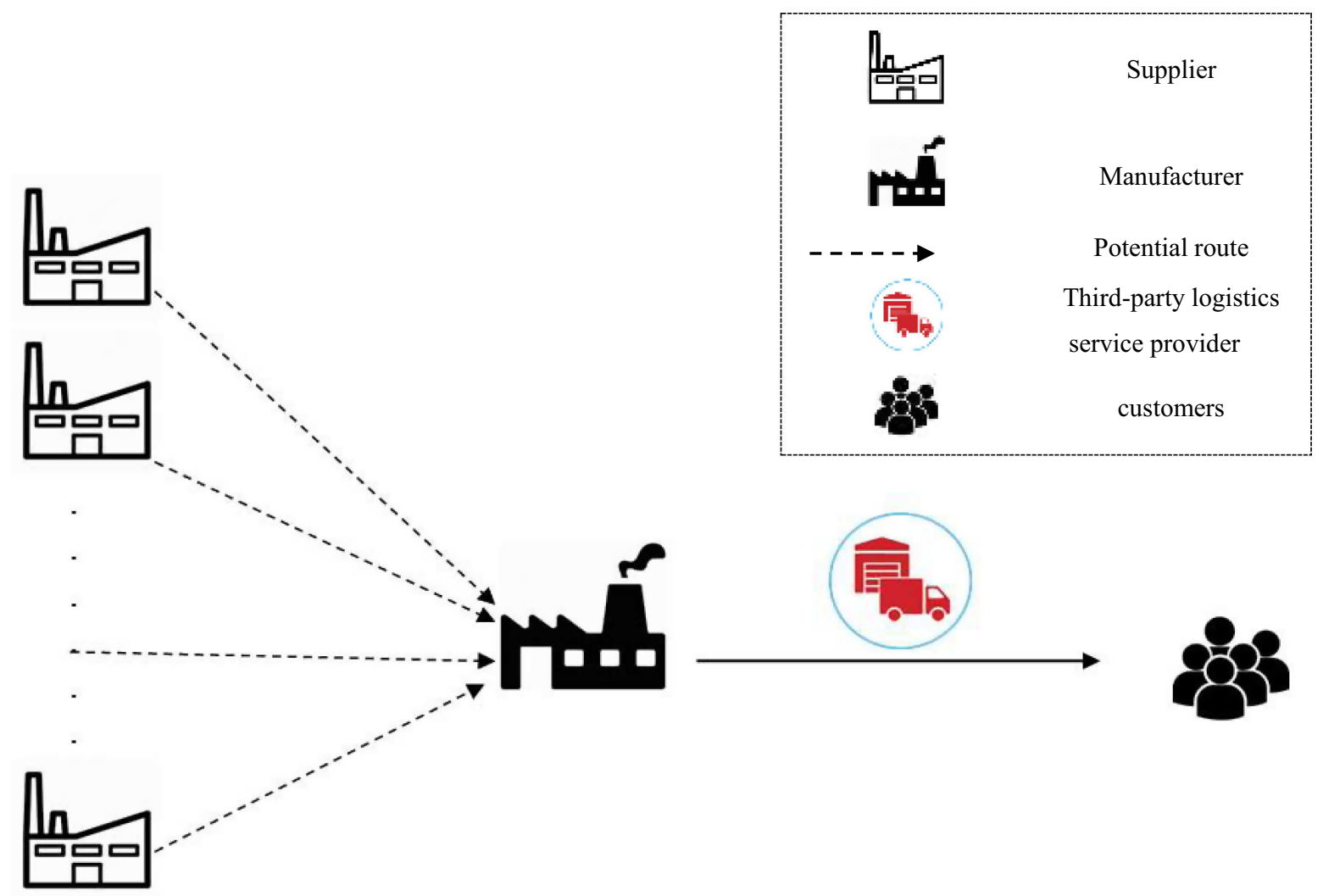

FiguRE 3. Schematic structure of the problem.

of batching and delivering, the production batches do not exceed the reserved number at the logistics corporatelevel. Therefore, a penalty charge is incurred by the logistics service provider in case the manufactured batches fall less than the reserved number.

In addition, as discussed before, a partnership supply chain entails its members to try for common interests. It is also assumed that the manufacturer has established long-term cooperation (i.e., strategic relationships) with both suppliers (the ones picked) and the logistics service provider. Therefore, we consider a situation where the taken suppliers (in a long-term relationships) and the logistics corporate do their works with no bug. Accordingly, we incorporate two kinds of penalties (imposed by the selected suppliers and the logistics provider) in the objective function.

In this formulation, we assume that the products are perishable, and so there is not any inventory storage. Moreover, the final products are delivered by a third-party logistics service which provides specified vehicles [with different capacities] with respect to the customers' demands, products features (such as expiration time lengths, shipping requirements), seasonal considerations, carbon emissions, capabilities of available transportation facilities, and other issues in each period. In order to keep the products fresh and incorporate the above requirements, each period is divided into several successive intervals through which the batches are manufactured. Thus, the whole demands may not be taken into account, and the vehicle capacity in a full truckload (FTL) shipment policy is targeted as the batch size for the manufacturer to achieve it. This leads to an advantageous approach in fulfilling the customers' demands, especially in the cited situation that the products are soon-expired. Over finite discrete-time periods, as the manufacturer's capacity is limited, backlogs are allowed. The manufacturer needs to select one or more suppliers (up to the maximum of two) based on the contract 
terms and also shipment charges. These measures express some operational performance goals that must be met. Even more, we consider a missed opportunity cost - composed of different issues such as lost sales, missed reputation and dependability in suppliers and the third-party logistics provider opinions, etc. - resulted from manufacturing defective items. This promotes the notion of a partnership supplying approach and stimulates the triple actors of the above supply chain to cooperate in presenting the right products and finally satisfying the customers' needs. Eventually, the buyer determines the raw material lot-sizes in each period, and develops a balanced production condition through minimizing the losses arising from different roots.

With the above description, the notations and a mixed-integer linear programming model are presented.

\subsection{Model parameters and decision variables}

\section{Indices}

$i$ Set of suppliers (agreed for long-term cooperation), $i=\{1,2,3, \ldots, I\}$.

$j$ Set of intervals in each period, $j=\left\{1,2,3, \ldots, B_{t}\right\}$.

$t$ Set of discrete-time periods, $t=\{1,2,3, \ldots, T\}$.

\section{Parameters}

$d_{t}^{\prime}$ Customers' demands of the product which are taken in period $t\left(d_{t}^{\prime}=B_{t} m_{t}\right)$.

$S_{i t}$ Initial fixed cost of ordering and signing contract with supplier $i$ in period $t$.

$S_{i t}^{\prime}$ Secondary fixed cost of ordering and signing contract with supplier $i$ in period $t\left(S_{i t}^{\prime}>S_{i t}\right)$.

$a_{i t}$ Cost of purchasing one unit of raw materials from supplier $i$ in period $t$ for the orders not exceeding the reserved capacity at supplier $i$.

$b_{i t}$ Cost of purchasing one unit of raw materials from supplier $i$ in period $t$ for the orders exceeding the reserved capacity at supplier $i\left(b_{i t}>a_{i t}\right)$.

$V_{i t}$ Reserved capacity (of raw materials) at supplier $i$ in period $t$.

$p_{i t}$ Unit penalty cost of ordering for deficit quantity of raw materials out of $V_{i t}$.

$C_{i t}$ Total capacity of supplier $i$ in procuring raw materials in period $t$.

$m_{t}$ Shipment capacity of the vehicle in period $t$ (which is pre-specified the default size of each production batch in period $t$ ).

$B_{t}$ Number of reserved transportation vehicles at the third-party logistics provider in period $t$ (which is pre-specified the default number of production batches in period $t$ ).

$\bar{B}_{t}$ Minimum number of production batches (delivery vehicles) that must be carried out in period $t$.

$t r_{i t}$ Unit shipment cost of raw materials from supplier $i$ to the manufacturer in the first order at period $t$.

$t r_{i t}^{\prime}$ Unit shipment cost of raw materials from supplier $i$ to the manufacturer in the second-order at period $t$ $\left(t r_{i t}^{\prime}>t r_{i t}\right)$.

$K_{t}$ Production capacity of the manufacturer in period $t$.

$f_{j}^{t}$ Fixed production cost of each batch in interval $j$ of period $t$.

$g_{t}$ Unit processing cost by the manufacturer in period $t$.

$l_{t}$ Fixed shipping cost paid to the third-party logistics provider for each batch in period $t$.

$\theta_{t}$ Unit penalty cost incurred by the third-party logistics provider for deficit number of batches out of $B_{t}$.

$r_{t}$ Unit missed opportunity cost caused by defective items manufactured in period $t$ (such as lost sales, missed reputation and dependability in suppliers and the third-party logistics provider opinions, etc.).

$\operatorname{pun}_{t}$ Punishing cost imposed by the third-party logistics service provider per manufactured batch in lessthan-truckload $\left(m_{t}\right)$ mode in period $t$ (composed of missed credit on customers' eyes, and also noneconomic shipping cost (penalty) in less-than-truckload (LTL) mode due to environmental violations) in the partnership strategy.

pen $_{i t}$ Unit penalty cost imposed by the supplier $i$ in period $t$ for the defective items manufactured from raw materials of supplier $i$ [this penalty includes loss of dependability among customers, rivals, logistics service provider, etc.) in the partnership strategy. 
$M$ A large amount.

$f_{j}^{t}$ Fixed production cost of each batch in interval $j$ of period $t$.

$g_{t}$ Unit processing cost by the manufacturer in period $t$.

$l_{t}$ Fixed shipping cost paid to the third-party logistics provider for each batch in period $t$.

\section{Decision variables}

$X_{i t}$ Quantity of raw materials ordered to supplier $i$ in price $a_{i t}$ (in period $t$ ).

$X_{i t}^{\prime}$ Quantity of raw materials ordered to supplier $i$ in price $b_{\text {it }}$ (in period $t$ ).

$Y_{i t}$ Binary variable indicating whether supplier $i$ gets an order in price $a_{i t}$ (1) or not (0) in period $t$.

$Y_{i t}^{\prime}$ Binary variable indicating whether supplier $i$ gets an order in price $b_{i t}(1)$ or not $(0)$ in period $t$.

$O_{j}^{t}$ Binary variable indicating whether the production batch in full-truckload $\left(m_{t}\right)$ mode is done or not at interval $j$ of period $t$.

$O_{j}^{\prime t}$ Binary variable indicating whether the production batch in less-than-truckload $\left(<m_{t}\right)$ mode is done or not at interval $j$ of period $t$.

$H_{j}^{t}$ Total quantity of faultless products manufactured at interval $j$ of period $t$.

$W_{i t}$ Quantity of defective items manufactured from raw materials of supplier $i$ in period $t$

$E_{t}$ Number of deficit batches out of $B_{t}$ in period $t$.

\subsection{Mathematical formulation}

Regarding the mentioned assumptions, parameters and decision variables, a MILP optimization model is expressed as follows:

$$
\begin{array}{rlr}
\operatorname{Min} Z= & \sum_{t=1}^{T} \sum_{i=1}^{I}\left[S_{i t} Y_{i t}+a_{i t} X_{i t}+S_{i t}^{\prime} Y_{i t}^{\prime}+b_{i t} X_{i t}^{\prime}+p_{i t}\left(V_{i t}-X_{i t}\right)\right] \\
& +\sum_{t=1}^{T} \sum_{i=1}^{I}\left(t r_{i t} X_{i t}+t r_{i t}^{\prime} X_{i t}^{\prime}\right)+\sum_{t=1}^{T} \sum_{j=1}^{J} f_{j}^{t}\left(O_{j}^{t}+O_{j}^{\prime t}\right) \\
& +\sum_{t=1}^{T} \sum_{i=1}^{J} g_{t}\left(X_{i t}+X_{i t}^{\prime}\right)+\sum_{t=1}^{T} \sum_{i=1}^{I} \operatorname{pen}_{i t} W_{i t}+\sum_{t=1}^{T} \sum_{j=1}^{J} l_{t}\left(O_{j}^{t}+O_{j}^{\prime t}\right) \\
& +\sum_{t=1}^{T} \theta_{t} E_{t}+\sum_{t=1}^{T} \sum_{j=1}^{J} \operatorname{pun}_{t} O_{j}^{\prime t}+\sum_{t=1}^{T} r_{t}\left(B_{t} m_{t}-\sum_{j=1}^{J} H_{j}^{t}\right) \\
\text { s.t. } \quad & \sum_{i=1}^{I}\left(X_{i t}+X_{i t}^{\prime}\right)=B_{t} m_{t} & \forall t=1,2, \ldots, T \\
& \sum_{i=1}^{I}\left(X_{i t}+X_{i t}^{\prime}-W_{i t}\right)=\sum_{j=1}^{I} H_{j}^{t} \quad \forall t=1,2, \ldots, T \\
& H_{j}^{t} \leq m_{t} \quad \forall j=1, \ldots, J \quad \forall t=1,2, \ldots, T \\
& \sum_{j=1}^{B_{t}} H_{j}^{t} \leq K_{t} \\
& \bar{B}_{t} \leq \sum_{j=1}^{J}\left(O_{j}^{t}+O_{j}^{\prime t}\right) \leq B_{t}
\end{array}
$$




$$
\begin{aligned}
& E_{t} \leq B_{t}-\sum_{j=1}^{J}\left(O_{j}^{t}+O_{j}^{\prime \prime}\right) \\
& X_{i t} \leq V_{i t} \\
& X_{i t}^{\prime} \leq C_{i t}-V_{i t}+1 \\
& X_{i t} \leq Y_{i t} M \\
& X_{i t}^{\prime} \leq Y_{i t}^{\prime} M \\
& I \\
& \sum_{i=1}^{I} Y_{i t} \leq 2 \\
& Y_{i t}^{\prime} \leq Y_{i t} \\
& O_{j}^{t}+O_{j}^{\prime t} \leq 1 \\
& X_{i t}, X_{i t}^{\prime}, W_{i t} \geq 0 \\
& H_{j}^{t} \geq 0 \\
& E_{t} \geq 0 \text { and integer } \\
& Y_{i t}, Y_{i t}^{\prime} \in\{0,1\} \\
& O_{j}^{t}, O_{j}^{\prime t} \in\{0,1\}
\end{aligned}
$$

$$
\begin{aligned}
& \forall t=1,2, \ldots, T \\
& \forall i=1,2, \ldots, I \quad \forall t=1,2, \ldots, T \\
& \forall i=1,2, \ldots, I \quad \forall t=1,2, \ldots, T \\
& \forall i=1,2, \ldots, I \quad \forall t=1,2, \ldots, T \\
& \forall i=1,2, \ldots, I \quad \forall t=1,2, \ldots, T \\
& \forall t=1,2, \ldots, T \\
& \forall i=1,2, \ldots, I \quad \forall t=1,2, \ldots, T \\
& \forall j=1, \ldots, J \quad \forall t=1,2, \ldots, T \\
& \forall i=1,2, \ldots, I \quad \forall t=1,2, \ldots, T \\
& \forall j=1, \ldots, J \quad \forall t=1,2, \ldots, T \\
& \forall t=1,2, \ldots, T \\
& \forall i=1,2, \ldots, I \quad \forall t=1,2, \ldots, T \\
& \forall j=1, \ldots, J \quad \forall t=1,2, \ldots, T .
\end{aligned}
$$

The objective function (Eq. (2.1)) minimizes the whole incurred costs including contract setting and ordering, purchasing, and penalties (first term), shipping raw materials from suppliers (second term), fixed manufacturing of batches(third term), processing charges of raw materials in manufacturing (fourth term), penalties imposed by selected suppliers (fifth term), dispatching batches to the customers (paid to the third-party logistics provider) (sixth term), reservation penalties incurred by the third-party logistics provider (seventh term), penalties imposed by the logistics corporate (such as losing credit on customers' viewpoints, non-economic shipping costs, etc.) (eighth term), and missed opportunity (ninth term). Equations (2.2) and (2.3) are the balancing restrictions connecting purchasing, manufacturing and delivery operations. Constraint (2.4) remarks that all manufactured products at each interval are bounded to the vehicle capacity in full-truckload mode (determining the batch size at each period]. Inequality (2.5) also indicates that the whole manufactured products do not exceed the operational capacity of the manufacturer. Constraint (2.6) ensures that all produced batches do not exceed the reserved number at the third-party logistics provider in each period (due to perishability requirements). The maximum number of batches in less-than-truckload is restricted by constraint (2.7). Inequalities (2.8) and (2.9) are related to the reservation and also capacity restrictions at each supplier, respectively. Constraints (2.10) and (2.11) are dependency limits showing that raw materials are purchased from a particular supplier only if it is elected for ordering. Constraint (2.12) ensures not exceeding the selected suppliers from a pre-defined number. Inequality (2.13) indicates another dependency restriction implying that a particular supplier is secondly ordered if it is chosen for the first time. Constraint (2.14) states the restriction corresponding 
to whether a manufactured batch size is entirely fulfilled or not at each interval. Finally, Constraints (2.15) to (2.19) are for the feasibility domain of each decision variable.

\section{The COMPleXity OF THE PROBLEM}

As we modified the classical SILSP and proposed a distinctive and novel configuration in satisfying the customers' demands, the problem is categorized in NP-hard class due to NP-hardness of simpler cases sited below. Following the matter, we use the notation offered by Akbalik et al. [3] in this way that $\left(K_{t}, a_{t}, b_{t}, p_{t}, R_{t}, V_{t}\right)$ specifies fixed ordering cost, per batch purchasing cost (when the number of batches ordered in period $t$ is less than the reserved capacity), per batch purchasing cost (when the number of batches ordered in period $t$ is more than the reserved capacity), unit purchasing cost, reserved batches in period $t$, and fixed size of each batch in period $t$ ), respectively. There are four classes of SILSP with batch ordering under the capacity reservation contract (SILSP-BOCRC) as NP-hard problems. For example, the problems where $\left(a_{t}=+\infty\right.$ and $V_{t}$ taking any optional quantity) or ( $V_{t}=0$ and $a_{t}$ taking any optional quantity) are related to the uncapacitated SILSPBOCRC. In these cases, there will be no reserved batch with the cost $a_{t}$ in an optimal solution. It is noted that when the reserved capacity is equal to zero $\left(V_{t}=0\right)$, the unit purchasing cost $a_{t}$ can take any optional quantity to be declined to the uncapacitated configuration. Another exceeding case is when $b_{t} \leq a_{t} \forall t \in\{1 \ldots T\}$. But as we have logically considered the second price $b_{t}$ more than the $a_{t}$, the mentioned case is ignored.

In this regard, Florian et al. [12] showed that the capacitated SILSP with fixed demands and zero backorder charges is NP-hard by making a reduction from the Knapsack Problem to a case of the problem (observe Florian et al. [12] Prop. 1, p. 671). Given that $b_{t}=+\infty$, the problem is changed into a capacitated SILSP. Moreover, by considering $K_{t}=1$, it is gained a unitary fixed ordering cost; and through setting $V_{t}=1$, per batch purchasing cost $a_{t}$ will changed the unit procurement charge in the proof of Proposition 1 in Florian et al. [12]. Thus, since the configuration $\left(K / a_{t} /+\infty /-/ R_{t} / V\right)$ - as a special case of $\left(K_{t}, a_{t}, b_{t}, p_{t}, R_{t}, V_{t}\right)$ - is NP-hard, our capacitated LSBPS problem also belongs to NP-hard classification.

Furthermore, in case the $V_{t}=1$, the SILSP with only a fixed ordering cost and variable capacities is the same as the problem investigated by Bitran and Yanasse [6]. They considered a case of the capacitated SILSP with varying capacities and fixed ordering costs where either both of them are assumed NI (non-increasing) or both of them ND (non-decreasing). They illustrated that upon these assumptions which are equal to the notation of $\left(K_{t},-,-,-, R_{t}, V\right)$, the problem is NP-hard even with no other charges (notice Bitran and Yanasse [6] Prop. 4, p. 1180).

As the same way, Akbalik and Rapine [2] indicated that the uncapacitated SILSP with batch production is NP-hard if per batch purchasing cost [when the number of batches ordered in period $t$ is more than the capacity reserved] and fixed size of each batch in period $t$ are variable, even with the whole other charges being zero. They reduced a case of the Unbounded Knapsack Problem (proven to be NP-complete by Lueker [18]) to the case of the uncapacitated SILSP stated above.

Summing up, as the simple cases investigated above are NP-hard, our capacitated LSBPS under two reservation contracts, along with supplier selection, is also classified as NP-hard in associated literature, implying that it is not possible to offer a solving algorithm with polynomial time complexity.

\section{Dynamic programming Algorithm}

We assume $T$ periods and in each period $t \in\{1,2,3, \ldots, T\}$, there are I suppliers in the joint supply chain (based on long-term agreements) suggesting different contracts.

\subsection{Assumptions}

To simplify the terminology of the main objective, we first consider some assumptions as follows:

- The transportation costs (incurred by shipping raw materials from suppliers to the manufacturer) are merged with the purchasing costs $\left(a_{i t}, b_{i t}\right)$. 
- Given the partnership supply approach, we consider the suppliers set as a whole, and thereby, the lost opportunity and penalty costs (imposed by the suppliers) are seamlessly included in pen $_{t}$.

- Following the simplicity requirements, we ignore the unit processing charges $g_{t} \sum_{i=1}^{I}\left(X_{i t}+X_{i t}^{\prime}\right)$ at each period.

- Less-than-truckload punishments are incurred in units of shortages instead of per batch, i.e., we replace the term $\sum_{j=1}^{J} \operatorname{pun}_{t} O_{j}^{\prime t}$ with $\sum_{j=1}^{B_{t}} \operatorname{pun}_{t}\left(m_{t}-H_{j}^{t}\right)$ in each period.

- We develop two scenarios, respectively, based on whether there is not any restriction on the number of orderings (Scenario 1) (Fig. 4) or we are limited by at most twice a period (Scenario 2) (Fig. 5).

\subsection{Scenario 1}

We first obtain the function $q_{i t}$ by the following equation:

$$
q_{i t}=\min _{i}\left\{S_{i t} \boldsymbol{\lambda}_{\mathbf{0}<\boldsymbol{X}_{i t} \leq \boldsymbol{V}_{i t}}+a_{i t} X_{i t}+p_{i t}\left(V_{i t}-X_{i t}\right) \boldsymbol{\lambda}_{\boldsymbol{X}_{i t}<\boldsymbol{V}_{i t}}\right\} \quad \forall t .
$$

where $\boldsymbol{\lambda}_{\delta}$ is equal to 1 when $\delta$ is true, and 0 , otherwise.

We assume that supplier $i_{j}$ has been taken for the first time according to the calculation above. Then, it is conducted a comparison scheme based on the terms below in case we need to order for the second time:

$$
\begin{aligned}
& q^{\prime}{ }_{i t}=\min _{i}\left\{\left(S_{i_{j} t}^{\prime} \boldsymbol{\lambda}_{\boldsymbol{X}_{j} t=\boldsymbol{V}_{i_{j} t}} \boldsymbol{\lambda}_{\left.\mathbf{0}<\boldsymbol{X}_{i_{j} t \leq C_{i_{j} t}-V_{i_{j} t}}^{\prime}+\boldsymbol{b}_{i_{j} t} \boldsymbol{X}_{\boldsymbol{i}_{j} t}^{\prime}\right)}\right),\right.
\end{aligned}
$$

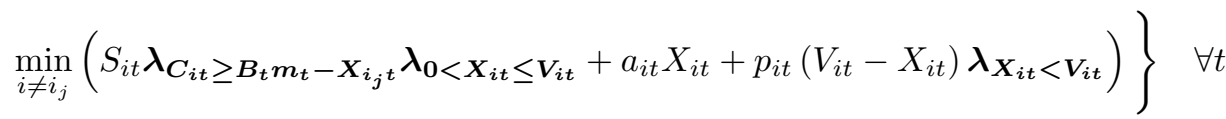

where $\boldsymbol{\lambda}_{\delta}$ is equal to 1 when $\delta$ is true, and 0 , otherwise.

Since the maximum number of suppliers captured must not exceed the pre-defined value 2, we are expected to do another assessment entailed due to distinctive outcomes from the previous step. In fact, this evaluation is incurred by the need for registering another order. It is carried out as follows:

(a) Supplier $i_{k}$ has been selected for the second time

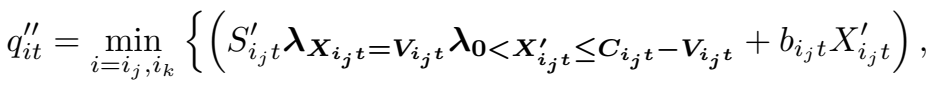

$$
\begin{aligned}
& \left.\left(S_{i_{k} t}^{\prime} \boldsymbol{\lambda}_{\boldsymbol{X}_{i_{k} t}=V_{i_{k} t}} \boldsymbol{\lambda}_{\mathbf{0}<\boldsymbol{X}_{\boldsymbol{i}_{k} t}^{\prime} \leq \boldsymbol{C}_{\boldsymbol{i}_{\boldsymbol{k}} t}-\boldsymbol{V}_{\boldsymbol{i}_{\boldsymbol{k}} t}}+b_{i_{k} t} X_{i_{k} t}^{\prime}\right)\right\} \quad \forall t
\end{aligned}
$$

where $\boldsymbol{\lambda}_{\delta}$ is equal to 1 when $\delta$ is true, and 0 , otherwise.

(b) Supplier $i_{j}$ has been again picked up for the second time

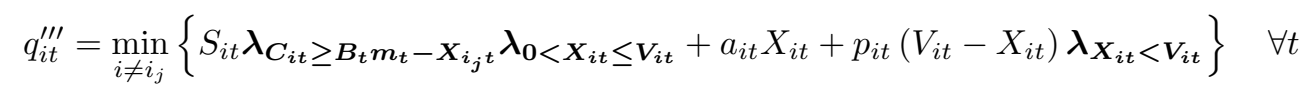

where $\boldsymbol{\lambda}_{\delta}$ is equal to 1 when $\delta$ is true, and 0 , otherwise.

\subsection{Scenario 2}

Incorporating the constraint based upon the whole number of orderings (at each period) makes the problem more practical. Although unlimited ordering brings about an intensely competitive environment between the suppliers to attract the manufacturer through offering preferable contracts, considering such restriction yields a situation in which the manufacturer tries to develop efficient processes and have optimal decision-making. Thus, we site below corresponding equations to realize the scenario 2's requirements. 


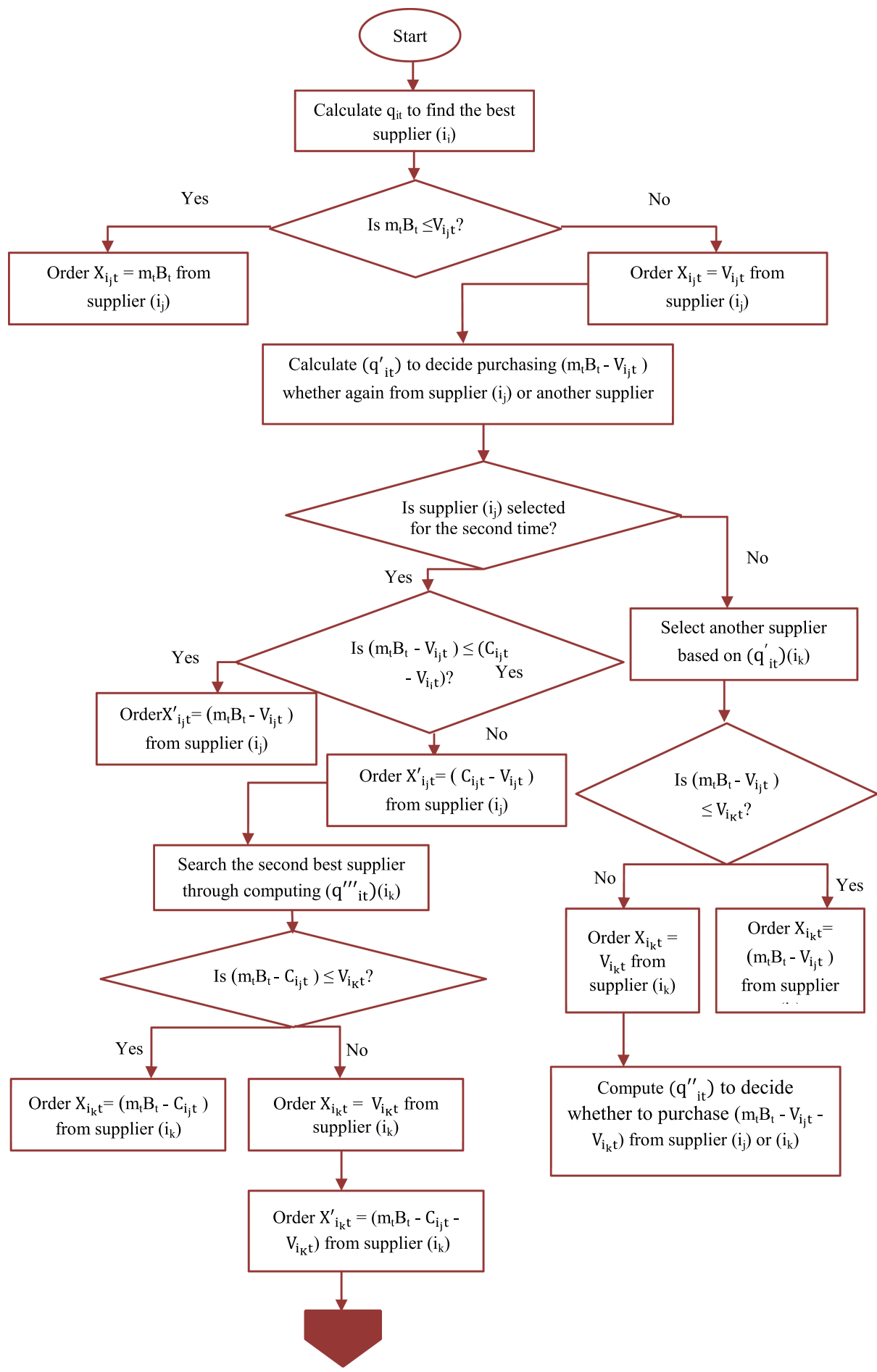

FIGURE 4. Flowchart of the DP algorithm for choosing the best supplier(s) and ordering the values needed based on scenario 1 . 


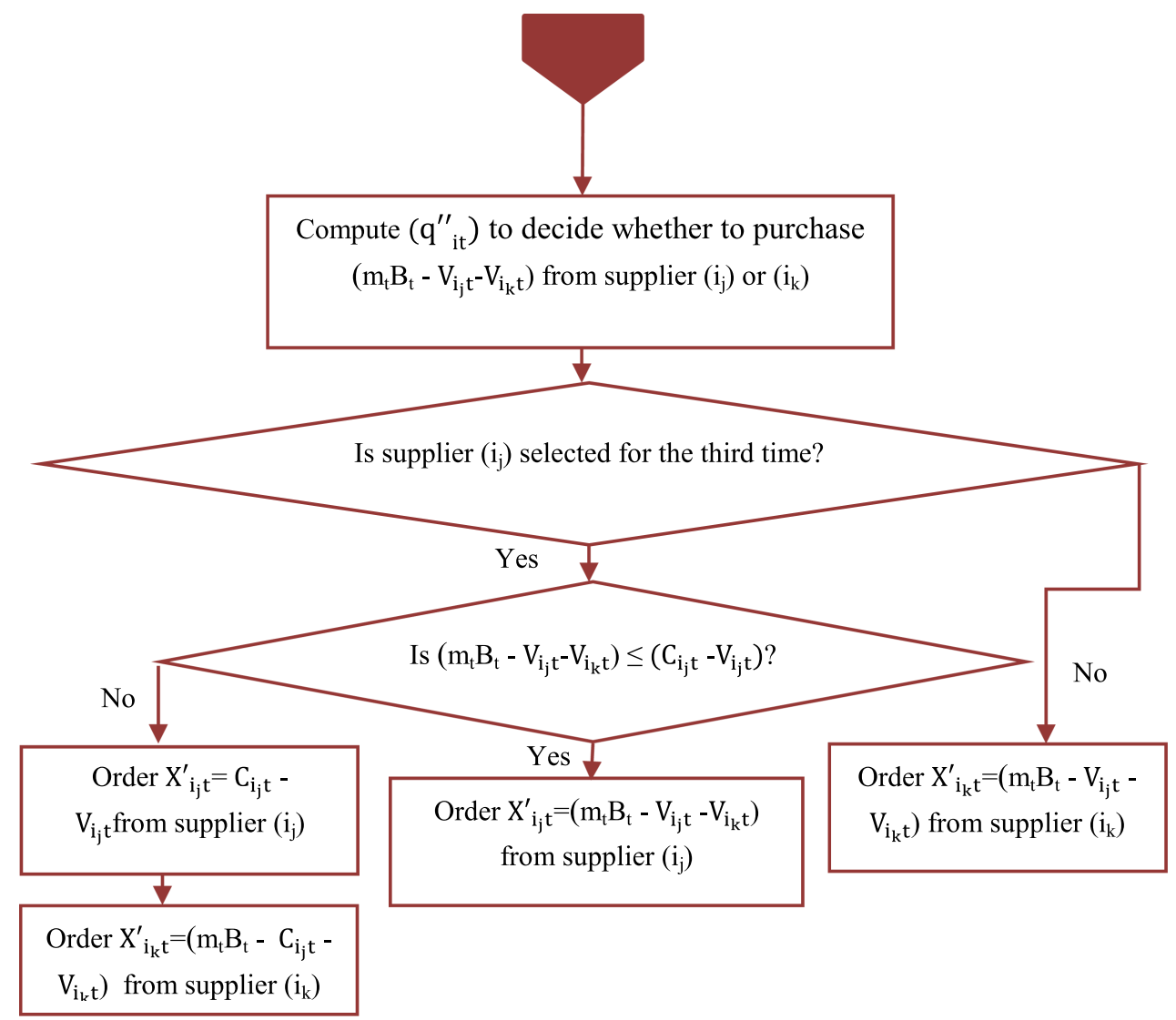

Figure 4. (Continued.)

First, we probe the best supplier according to the equation primarily proposed in the previous scenario $\left(q_{i t}\right)$.

$$
q_{i t}=\min _{i}\left\{S_{i t} \boldsymbol{\lambda}_{\mathbf{0}<\boldsymbol{X}_{i t} \leq \boldsymbol{V}_{i t}}+a_{i t} X_{i t}+p_{i t}\left(V_{i t}-X_{i t}\right) \boldsymbol{\lambda}_{\boldsymbol{X}_{i t}<V_{i t}}\right\} \quad \forall t
$$

where $\boldsymbol{\lambda}_{\delta}$ is equal to 1 when $\delta$ is true, and 0 , otherwise.

It is assumed that supplier $i_{j}$ has been selected for the first time. Afterward, we need to carry out another selection with the purpose of providing the intended size of raw materials at each period. Hence, we consider two conditions as follows:

(a) Quantities needed $\left(B_{t} m_{t}\right)$ is more than the reserved capacity at supplier $i_{j}\left(X_{i_{j} t}=V_{i_{j} t}\right)$

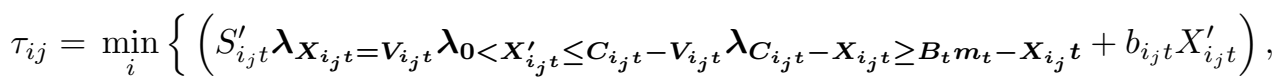

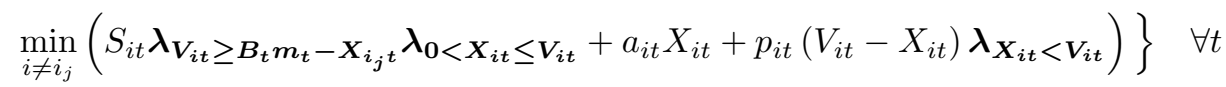

where $\boldsymbol{\lambda}_{\delta}$ is equal to 1 when $\delta$ is true, and 0 , otherwise.

(b) Quantities needed are less than the reserved capacity at the supplier $i_{j}\left(X_{i_{j} t}=B_{t} m_{t}\right)$

Under the above assumption, there is no need to register a new order.

To better understand, the flowcharts of the dynamic programming (DP) algorithms for the above-stated scenarios are respectively illustrated in Figures 4 and 5. 


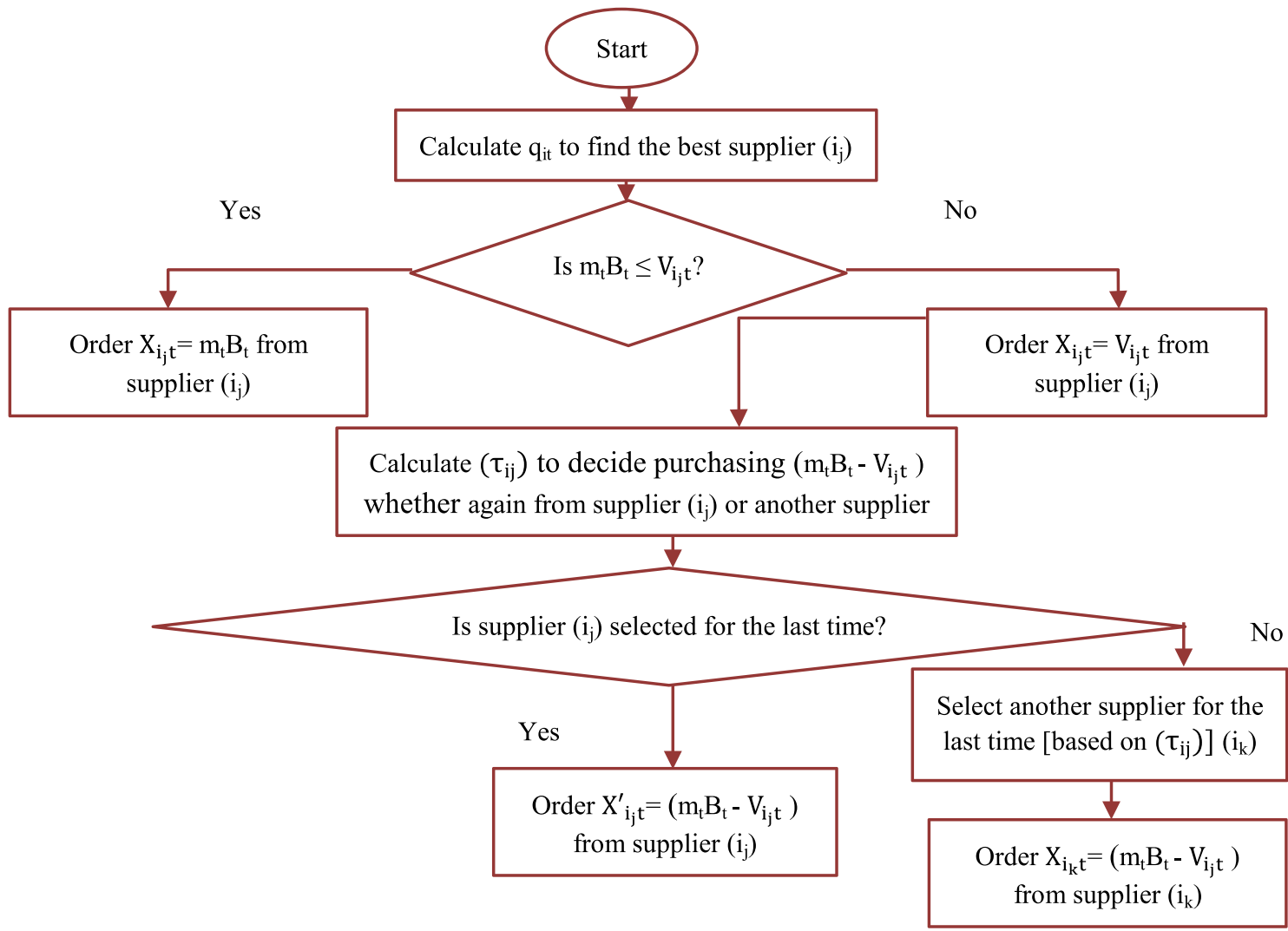

FIGURE 5. Flowchart of the DP algorithm for choosing the best supplier(s) and ordering the values needed based on scenario 2 .

Hereafter, we try to gain the function $\beta_{t}$ as follows:

$$
\begin{aligned}
\min _{H_{j}^{t}} \beta_{t}= & {\left[\left(\sum_{j=1}^{B_{t}} f_{j}^{t}\left\lceil\frac{H_{j}^{t}}{m_{t}}\right\rceil+l_{t} \sum_{j=1}^{B_{t}}\left\lceil\frac{H_{j}^{t}}{m_{t}}\right\rceil\right) \boldsymbol{\lambda}_{\boldsymbol{H}_{j}^{t}>\mathbf{0}}^{\prime}+\operatorname{pen}_{t}\left(B_{t} m_{t}-\sum_{j=1}^{B_{t}} H_{j}^{t}\right) \boldsymbol{\lambda}_{\mathbf{0}<\sum_{j=1}^{B_{t}} \boldsymbol{H}_{j}^{t}<\boldsymbol{B}_{\boldsymbol{t}} \boldsymbol{m}_{\boldsymbol{t}}}\right.} \\
& \left.+\theta_{t}\left(B_{t}-\sum_{j=1}^{B_{t}}\left\lceil\frac{H_{j}^{t}}{m_{t}}\right\rceil\right) \boldsymbol{\lambda}_{\sum_{j=1}^{B_{t}}\left\lceil\frac{\boldsymbol{H}_{j}^{t}}{M_{\boldsymbol{t}}}\right\rceil<\boldsymbol{B}_{t}}+\sum_{j=1}^{B_{t}} \operatorname{pun}_{t}\left(m_{t}-H_{j}^{t}\right) \boldsymbol{\lambda}_{\mathbf{0}<\boldsymbol{H}_{j}^{\prime}<\boldsymbol{m}_{t}}^{\prime}\right] \forall t
\end{aligned}
$$

where $\boldsymbol{\lambda}_{\delta}^{\prime}$ is equal to 1 when $\delta$ is true, and 0 , otherwise.

Drawing on the equation above, we develop another DP algorithm to address the manufacturing delivery operations as well. Therefore, the steps of the algorithm are illustrated in Table 1.

\subsection{Numerical study}

Note that the time complexity of the solving algorithm (in context of an overall procedure) is in $\mathrm{O}(T I \cdot T)$ and $\mathrm{O}\left(T I^{2}(I-1) \cdot T B_{t} J\right)$, illustrating the best and worst cases, respectively. Once the $\mathrm{O}\left(T I^{2}(I-1)\right)$ or $\mathrm{O}(T I)$ values are gained [respectively in scenarios 1 and 2] for the optimal cost of the manufacturer, we can then compute the overall complexity with respect to the values captured in the second phase [according to the DP algorithm suggested for the manufacturing and delivery sections]. As stated, the complexity of DP is dependent on $T, I, B_{t}$, 
TABle 1. Pseudo-code of DP algorithm in the manufacturing-delivery operations.

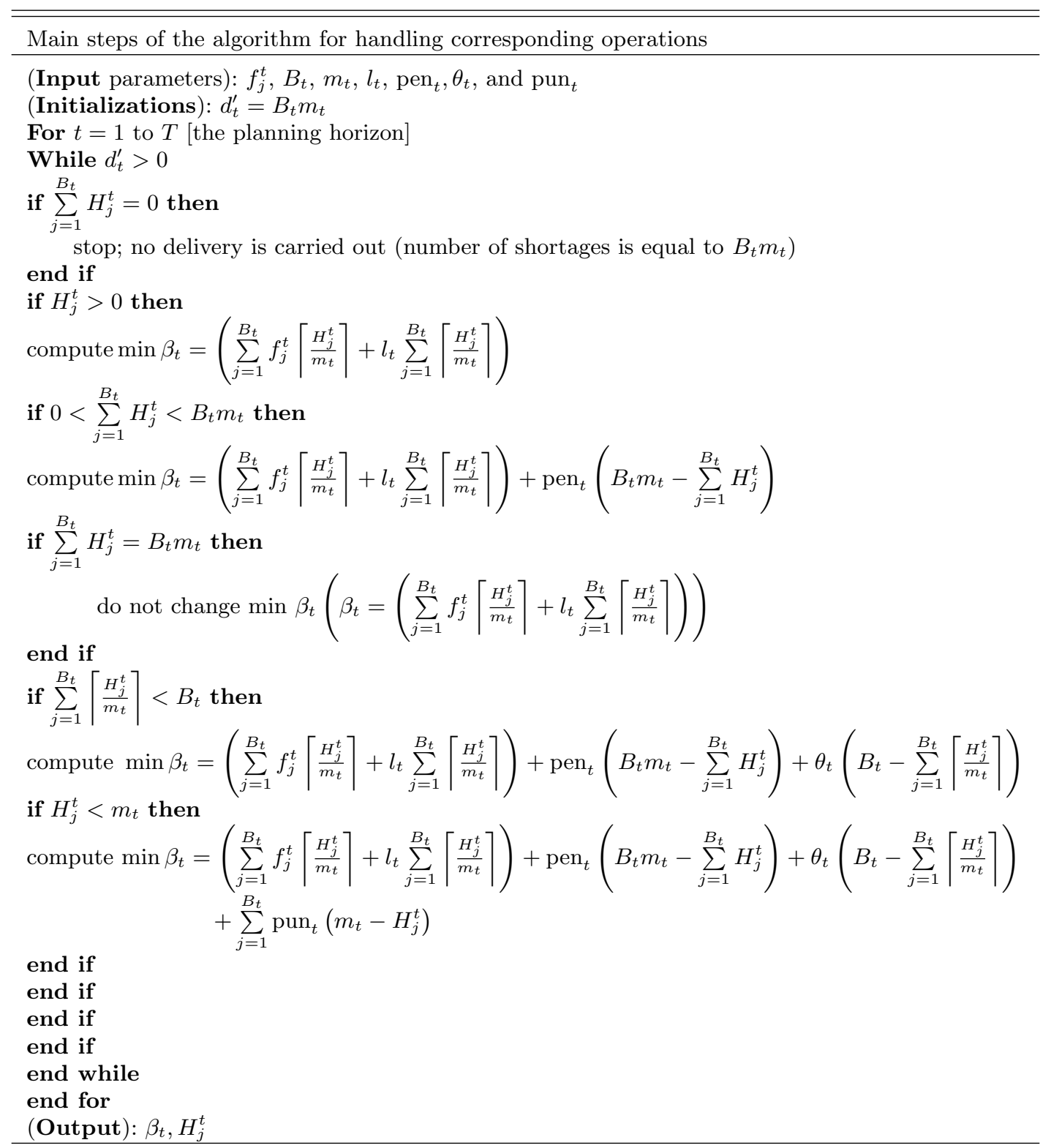

and $J$ in the worst case, which respectively are the length of time horizon, the suppliers joint to the long-term agreement, the number of batches, and the number of intervals. On the other hand, the computational time of MILP formulation is thoroughly unpredictable and it is determined with respect to the whole parameters of the problem.

For experimental evaluation of the proposed approach, we consider below a particular illustration of the problem. As seen in Table 2, the instance consists of three suppliers that are to be assessed within three periods of time. Since there is no similar study with full coverage in the literature, we tried to determine the values of corresponding parameters with the help of some researches such as Akbalik et al. [3]. The cited parameters 
TABLE 2. An illustration of the problem.

\begin{tabular}{|c|c|c|c|c|c|c|c|c|c|c|c|c|c|c|c|c|c|c|c|c|}
\hline Supplier & Period & $d_{t}^{\prime}=B_{t} m_{t}$ & $S_{i t}$ & $S_{i t}^{\prime}$ & $a_{i t}$ & $b_{i t}$ & $V_{i t}$ & $p_{i t}$ & $C_{i t}$ & $t r_{i t}$ & $t r_{i t}^{\prime}$ & $K_{t}$ & $f_{t}$ & $g_{t}$ & $l_{t}$ & $\theta_{t}$ & $r_{t}$ & $\operatorname{pun}_{t}$ & pen $_{i t}$ & $Z$ \\
\hline \multirow[t]{3}{*}{1} & 1 & 170 & 150 & 161 & 41 & 49 & 78 & 28 & 100 & 18 & 23 & 173 & 250 & 59 & 140 & 75 & 46 & 35 & 31 & 123845 \\
\hline & 2 & 183 & 160 & 172 & 40 & 48 & 136 & 30 & 150 & 19 & 24 & 190 & 266 & 68 & 155 & 79 & 49 & 43 & 30 & 175248 \\
\hline & 3 & 200 & 155 & 168 & 43 & 50 & 155 & 31 & 174 & 21 & 25 & 210 & 275 & 79 & 161 & 81 & 53 & 45 & 33 & 179869 \\
\hline \multirow[t]{3}{*}{2} & 1 & 170 & 187 & 197 & 39 & 47 & 100 & 30 & 126 & 25 & 28 & 173 & 250 & 59 & 140 & 75 & 46 & 35 & 44 & 119989 \\
\hline & 2 & 183 & 199 & 210 & 45 & 51 & 170 & 33 & 185 & 17 & 20 & 190 & 266 & 68 & 155 & 79 & 49 & 43 & 45 & 199899 \\
\hline & 3 & 200 & 205 & 214 & 49 & 59 & 168 & 33 & 170 & 14 & 19 & 210 & 275 & 79 & 161 & 81 & 53 & 45 & 41 & 150502 \\
\hline \multirow[t]{3}{*}{3} & 1 & 170 & 136 & 166 & 48 & 58 & 95 & 25 & 101 & 22 & 24 & 173 & 250 & 59 & 140 & 75 & 46 & 35 & 52 & 139666 \\
\hline & 2 & 183 & 155 & 175 & 55 & 61 & 99 & 28 & 123 & 24 & 26 & 190 & 266 & 68 & 155 & 79 & 49 & 43 & 50 & 133665 \\
\hline & 3 & 200 & 144 & 165 & 58 & 65 & 199 & 34 & 205 & 13 & 18 & 210 & 275 & 79 & 161 & 81 & 53 & 45 & 55 & 196112 \\
\hline \multirow[t]{3}{*}{4} & 1 & 170 & 176 & 188 & 39 & 44 & 130 & 19 & 130 & 16 & 19 & 173 & 250 & 59 & 140 & 75 & 46 & 35 & 49 & 185859 \\
\hline & 2 & 183 & 169 & 179 & 39 & 47 & 110 & 29 & 118 & 23 & 29 & 190 & 266 & 68 & 155 & 79 & 49 & 43 & 49 & 178965 \\
\hline & 3 & 200 & 149 & 155 & 45 & 54 & 172 & 27 & 199 & 19 & 23 & 210 & 275 & 79 & 161 & 81 & 53 & 45 & 45 & 166252 \\
\hline
\end{tabular}

TABLE 3. A comparison scheme between MILP and the heuristic approaches.

\begin{tabular}{lllllll}
\hline \hline & \multicolumn{3}{c}{$T=6$} & \multicolumn{3}{c}{$T=15$} \\
\cline { 2 - 7 } & $I=10$ & $I=15$ & $I=30$ & $I=10$ & $I=15$ & $I=25$ \\
\hline $\begin{array}{l}\text { CPU time of heuristic algorithm } \\
\text { based on scenario 1 (s) }\end{array}$ & 0.062 & 0.16 & 2.66 & 4.09 & 8.89 & 10.02 \\
$\begin{array}{l}\text { CPU time of heuristic algorithm } \\
\text { based on scenario 2 (s) }\end{array}$ & 0.013 & 0.022 & 0.11 & 2.28 & 5.09 & 6.93 \\
CPU time of MILP (s) & & & & & & \\
Gap in DP completion of scenario 1 & 0.362 & 1.18 & 1.02 & 2.81 & 1.99 & 16.23 \\
Gap in DP completion of scenario 2 & 0 & 0 & 0 & 0 & 0.009 & 0 \\
Gap at MILP completion & 0 & 0 & 0 & 0 & 0 & 0.0015 \\
\hline
\end{tabular}

are illustrated in different columns of the table. Noting the $Z$ column illustrating the whole incurred charges, we can observe that suppliers 2 and 3 provide more preferable conditions comparing to the supplier 1 . In this regard, supplier 2 is considered as the option with the highest priority for developing partnership relationships.

To test the efficiency of the heuristic algorithms offered in the corresponding sections, we now compare the performances of MILP and DP algorithms based on the measure of CPU time and the gaps in Table 3.

Figure 6 illustrates an analysis based on productivity measure to prove the preferable advantage of the problem in decreasing the manufacturing losses.

\subsubsection{Sensitivity analysis}

In this section, some beneficial sensitivity analyses are carried out according to the penalty measures imposed by different echelons of the under-discussion supply chain. Accordingly, we investigate the impacts of parameters $\theta_{t}, \operatorname{pun}_{t}$ and pen $_{t}$ on $Z$ (objective function) within six three-dimensional diagrams. As seen in Figure 7, there exists an ascending relation between the $Z$ and the triple penalties $\left(\theta_{t}, \operatorname{pun}_{t}\right.$, pen $\left._{t}\right)$. In other words, increasing values of $\left(\theta_{t}, \operatorname{pun}_{t}\right.$, pen $\left._{t}\right)$ result in rising costs as well. In this regard, the objective function of scenario 2 illustrates more growth comparing to that of scenario 1.

\subsection{Managerial insights}

Table 2 provides a combination of parameters (e.g., customers' demands, reserved capacity, penalty costs and etc.) within a particular instance. As shown in the numerical example, it is highly important to observe the overall performances of the included suppliers. Accordingly, pointing out the whole incurred charges (the $Z$ column), we can acknowledge that the suppliers 2 and 3 bring forward more affordable conditions comparing to 


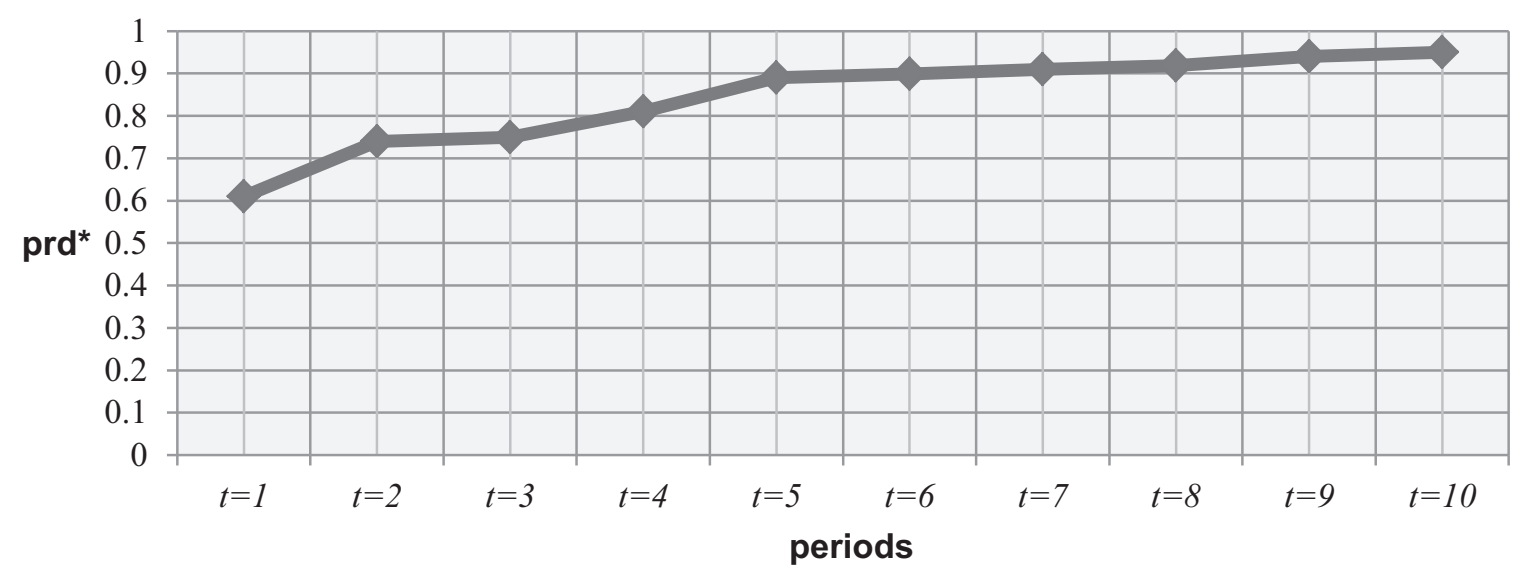

$* \operatorname{prd}=\sum_{i=1}^{I}\left(X_{i t}+X^{\prime}{ }_{i t}\right) / \sum_{j=1}^{J} H_{j}^{t}$

Figure 6. Productivity analysis at each period illustrating a progressive approach.

the supplier 1. In other words, when analyzing the suppliers' performances through a three-period horizon, the choices will be supplier 2, 3 and gain 2, respectively. This specifies how to develop a partnership structure in supply chains. Therefore, supplier 2 is considered as the most convincing option for developing such partnerships.

A comparison scheme has been presented within Table 3. In this table, CPU time and the absolute optimization gap are considered as the evaluation criteria. Also, two horizons of 6 and 15 time-periods have been assigned for the assessment wherein the problem is solved based on the MILP formulation and the developed scenarios as well. As observed, in most cases, the cited scenarios provide more efficient performances. Further, it is noteworthy that the solving procedure developed based on scenario 2 and the manufacturing-delivery algorithm is mostly preferred.

A productivity analysis has been also developed in Figure 6. It illustrates the preferable advantage of the suggested approach - single-item lot-based supplying and batch production under a bilateral capacity reservation contract - in decreasing the manufacturing losses. In this regard, the relation $\sum_{i=1}^{I}\left(X_{i t}+X_{i t}^{\prime}\right) / \sum_{j=1}^{J} H_{j}^{t}$ indicates the ratio of items purchased from suppliers to the number of faultless products in different periods. The ascending trend of the diagram designates an uninterrupted improvement in the under-investigation time horizon. Hence, establishing the supply and manufacturing communications (in supply chains) based on the proposed approach can lead to the further development of partnership structures and waste reductions as well.

\section{Conclusion And Future REMARKS}

Lot-sizing and batch-production of perishable products, along with the supplier selection process simultaneously address the sourcing and delivery operations. It is always worth providing a balanced production scheme and developing a partnership supply procedure in all kinds of enterprises. Indeed, establishing a coordination structure in the context of supplying, manufacturing, and deliveries supports the notion of decreased undesirability. Taking the right suppliers and dividing lot-sizes among them become a major challenge for a decision-maker when suppliers offer non-negligible contracts with certain delivery performance. Our work opens appealing research avenues through considering a progressive improvement approach in a particular supply chain. In this regard, we study a single-item lot-based supplying and batch production under a bilateral capacity reservation contract based on a partnership supply strategy. Further, the products are perishable and delivered by a third-party logistics provider specifying the batch-size of the production with respect to the products' delivery requirements, customers' demands, and other considerations. This implies a mechanism in which two short-term contracts are signed with the selected suppliers and a third-party logistics provider, respectively. In fact, we 
a)

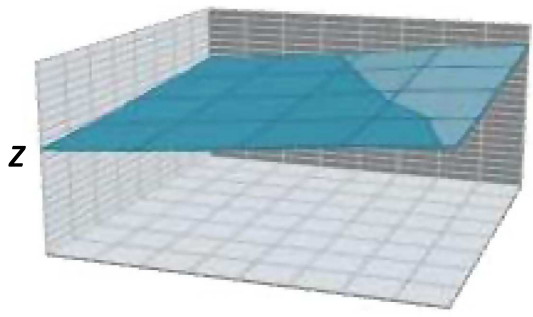

pun $_{t}$

c)

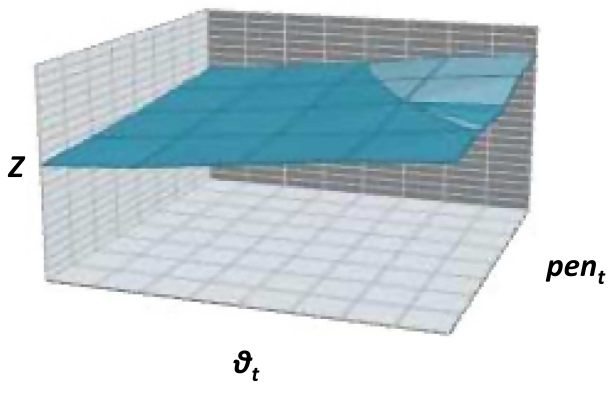

e)

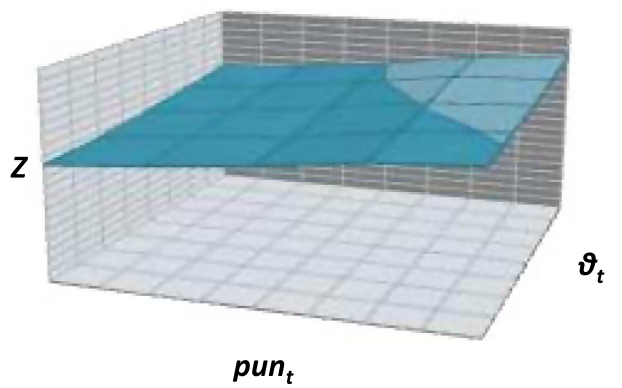

b)

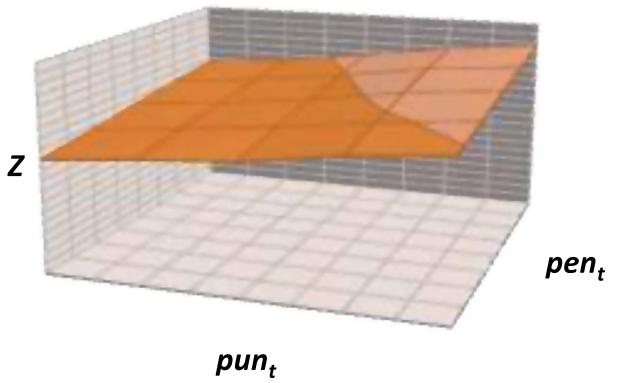

d)

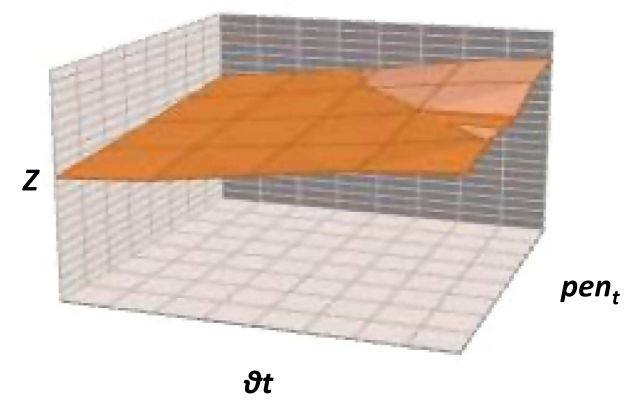

f)

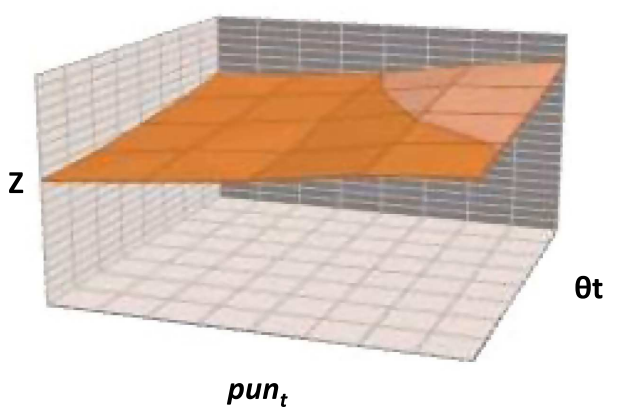

Figure 7. The effects of $\left(\theta_{t}, \operatorname{pun}_{t}, \operatorname{pen}_{t}\right)$ on the total cost. (a) The effects of $\left(\operatorname{pun}_{t}, \operatorname{pen}_{t}\right)$ on the whole cost $(Z)$ in scenario 1. (b) The effects of $\left(\operatorname{pun}_{t}, \operatorname{pen}_{t}\right)$ on the whole cost $(Z)$ in scenario 2. (c) The effects of $\left(\theta_{t}\right.$, pen $\left._{t}\right)$ on the whole cost $(Z)$ in scenario 1. (d) The effects of $\left(\theta_{t}\right.$, pen $\left._{t}\right)$ on the whole cost $(Z)$ in scenario 2. (e) The effects of $\left(\theta_{t}, \operatorname{pun}_{t}\right)$ on the whole cost $(Z)$ in scenario 1 . (f) The effects of $\left(\theta_{t}, \operatorname{pun}_{t}\right)$ on the whole cost $(Z)$ in scenario 2.

develop a partnership supply chain where the manufacturer is a focal point of the network. There are strategic (long-term) cooperation agreements among the manufacturer, suppliers (the ones taken), and the logistics provider. Accordingly, in addition to the ordinary costs incurred due to ordering and delivery processes, some penalties are imposed for orders/delivers exceeding or falling behind the reserved capacity. In another point of view, although it is straightforward to observe that the capacity reservation models (in general formulations) are more difficult than the capacitated lot-sizing problem, we investigated the complexity of the problem in the corresponding section, showing the NP-hardness of solving its model. Hence, we proposed three dynamic programming (DP) algorithms to reduce the problem complexity. We computed the overall complexity of the algorithms with time $\mathrm{O}(T I \cdot T)$ and $\mathrm{O}\left(T I^{2}(I-1) \cdot T B_{t} J\right)$ in the best and worst cases, respectively. 
Among the possible research perspectives of this work, one can consider the uncertainty of the parameters required in practical issues in the first extension. Second, incorporating scheduling decisions such as due dates of the products and delivery time windows are also striking. Further, the problem becomes more interesting when investigating other reservation contracts with more complex cost structures, which can also vary with time. Another perspective is to study the current model in the multi-item cases. Another direction is to propose the metaheuristic algorithm to solve the problem, especially for large-size instances.

Acknowledgements. The authors would like to thank the reviewers for their detailed comments and suggestions for the paper.

\section{Conflicts of interest}

No potential conflict of interest was reported by the authors.

\section{REFERENCES}

[1] N. Absi, S. Kedad-Sidhoum and S. Dauzère-Pérès, Uncapacitated lot-sizing problem with production time windows, early productions, backlogs and lost sales. Int. J. Prod. Res. 49 (2011) 2551-2566.

[2] A. Akbalik and C. Rapine, The single item uncapacitated lot-sizing problem with time-dependent batch sizes: NP-hard and polynomial cases. Eur. J. Oper. Res. 229 (2013) 353-363.

[3] A. Akbalik, A.B. Hadj-Alouane, N. Sauer and H. Ghribi, NP-hard and polynomial cases for the single-item lot sizing problem with batch ordering under capacity reservation contract. Eur. J. Oper. Res. 257 (2017) 483-493.

[4] Z. Alipour, F. Jolai, E. Monabbati and N. Zaerpour, General lot-sizing and scheduling for perishable food products. RAIRO:OR 54 (2020) 913-931.

[5] Y. Bian, D. Lemoine, T.G. Yeung and N. Bostel, Two-level uncapacitated lot-sizing problem considering the financing cost of working capital requirement. Front. Eng. Manage. (2020) 1-11.

[6] G.R. Bitran and H.H. Yanasse, Computational complexity of the capacitated lot size problem. Manage. Sci. 28 (1982) $1174-1186$.

[7] N. Brahimi, S. Dauzère-Pérès, N.M. Najid and A. Nordli, Single item lot sizing problems. Eur. J. Oper. Res. 168 (2006) 1-16.

[8] N. Brahimi, N. Absi, S. Dauzère-Pérès and S. Kedad-Sidhoum, Models and Lagrangian heuristics for a two-level lot-sizing problem with bounded inventory. OR Spect. 37 (2015) 983-1006.

[9] N. Brahimi, N. Absi, S. Dauzère-Pérès and A. Nordli, Single-item dynamic lot-sizing problems: an updated survey. Eur. J. Oper. Res. 263 (2017) 838-863.

[10] D. Choudhary and R. Shankar, A goal programming model for joint decision making of inventory lot-size, supplier selection and carrier selection. Comput. Ind. Eng. 71 (2014) 1-9.

[11] C. Chu, F. Chu, J. Zhong and S. Yang, A polynomial algorithm for a lot-sizing problem with backlogging, outsourcing and limited inventory. Comput. Ind. Eng. 64 (2013) 200-210.

[12] M. Florian, J.K. Lenstra and A.H.G. Rinnooy Kan, Deterministic production planning: algorithms and complexity. Manage. Sci. 26 (1980) 669-679.

[13] H.C. Hwang and J. Kang, The two-level lot-sizing problem with outbound shipment. Omega 90 (2020) 101997.

[14] M.A.A. Khan, A.A. Shaikh, G.C. Panda and I. Konstantaras, Two-warehouse inventory model for deteriorating items with partial backlogging and advance payment scheme. RAIRO:OR 53 (2019) 1691-1708.

[15] M.A.A. Khan, A.A. Shaikh, G.C. Panda, I. Konstantaras and A.A. Taleizadeh, Inventory system with expiration date: pricing and replenishment decisions. Comput. Ind. Eng. 132 (2019) 232-247.

[16] M.A.A. Khan, A.A. Shaikh, G.C. Panda, A.K. Bhunia and I. Konstantaras, Non-instantaneous deterioration effect in ordering decisions for a two-warehouse inventory system under advance payment and backlogging. Ann. Oper. Res. (2020) 1-33.

[17] M.A.A. Khan, A.A. Shaikh, G.C. Panda, I. Konstantaras and L.E. Cárdenas-Barrón, The effect of advance payment with discount facility on supply decisions of deteriorating products whose demand is both price and stock dependent. Int. Trans. Oper. Res. 27 (2020) 1343-1367.

[18] G.S. Lueker, Two NP-complete Problems in Nonnegative Integer Programming. Report No. 178, Computer Science Laboratory, Princeton University, NJ (1975).

[19] G.C. Panda, M.A.A. Khan and A.A. Shaikh, A credit policy approach in a two-warehouse inventory model for deteriorating items with price-and stock-dependent demand under partial backlogging. J. Ind. Eng. Int. 15 (2019) 147-170.

[20] S.L. Phouratsamay, S. Kedad-Sidhoum and F. Pascual, Two-level lot-sizing with inventory bounds. Discrete Optim. 30 (2018) $1-19$.

[21] A.A. Shaikh, S.C. Das, A.K. Bhunia, G.C. Panda and M.A.A. Khan, A two-warehouse EOQ model with interval-valued inventory cost and advance payment for deteriorating item under particle swarm optimization. Soft Comput. 23 (2019) $13531-13546$.

[22] A.A. Taleizadeh, Lot-sizing model with advance payment pricing and disruption in supply under planned partial backordering. Int. Trans. Oper. Res. 24 (2017) 783-800. 
[23] A.A. Taleizadeh, S. Tavakoli and L.A. San-José, A lot sizing model with advance payment and planned backordering. Ann. Oper. Res. 271 (2018) 1001-1022.

[24] M. Van Vyve, Linear-programming extended formulations for the single-item lot-sizing problem with backlogging and constant capacity. Math. Program. 108 (2006) 53-77.

[25] H.M. Wagner and T.M. Whitin, Dynamic version of the economic lot size model. Manage. Sci. 5 (1958) 89-96.

[26] W.I. Zangwill, A backlogging model and a multi-echelon model of a dynamic economic lot size production system - a network approach. Manage. Sci. 15 (1962) 506-527. 